\section{LIFE-HISTORY OF THE LIVER-FLUKE.}

Prof. A. P. Thomas, now of Auckland, New Zealand, has published in full the results of his valuable and important researches on the development of the liver-parasites, which produce the so-called 'rot,' - a disease that is especially fatal to sheep, but sometimes occurs in man. It is estimated to have occasioned the loss of some $3,000,000$ sheep in Great Britain during the winter of 1879-80. Leuckart has also studied this subject, and reported his observations in the Zoologischen anzeiger for Oct. 9, 1882. Thomas's results, as given in the Quarterly journal of microscopical science for January, 1883, are remarka- the time needed to produce the embryos: hence a field once infested remains dangerous for a long time. The embryo enlarges at the expense of the nutritive material (so-called yolk-cells, though they have nothing to do with the yolk), and, when mature, bursts open the operculum of the egg-shell, and immediately begins swimming freely in the water. Its form is an elongated cone ( $0.13 \mathrm{~mm}$. long), with rounded apex, as is shown in fig. A of the accompanying cut. The base of the cone is directed forwards, and in its centre is a short retractile head-papilla, $p r$. The whole surface is covered with cilia, which are borne by the large ectodermal cells. In the interior are two eyes, oc, and other structures, which are very briefly
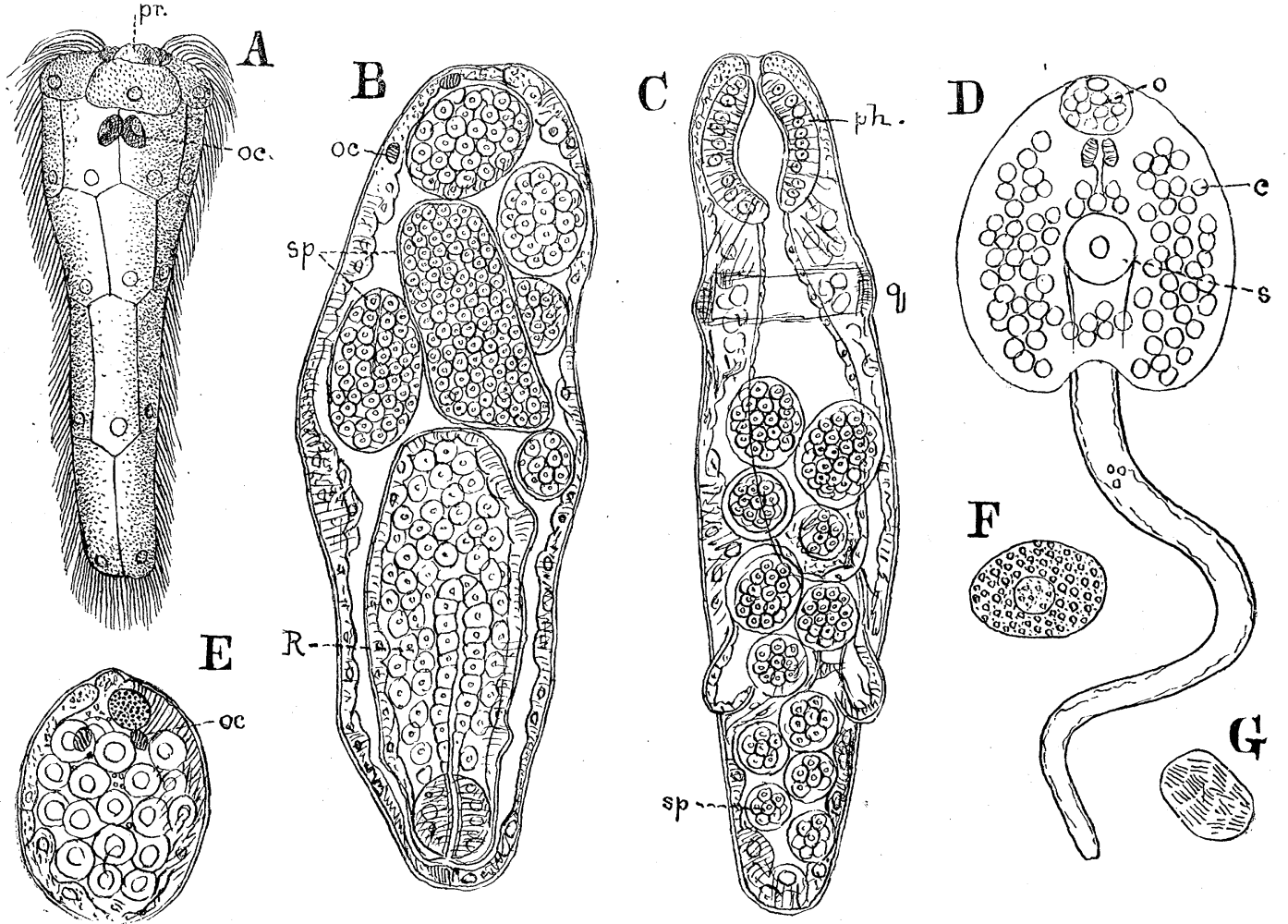

Expranatron of figures. - A, embryo; B, sporocyst; C, redia; D, cercaria; E, young sporocyst; F, cystogenous cell; G, pod cell from cercaria. $o c$, ocelli; $s p$, spores; $R$, redia; $p h$, pharynx; $q$, collar of redia; $c$, cystogenous cells; $s$, sucker.

bly complete; and, as they are of general interest, we present an abstract of them.

The adult worm (Distomum hepaticum) infests the liver of mammals. It discharges its eggs into the bileducts, which they sometimes clog. The eggs then pass into the intestines, and may be found abundantly in the droppings of the host. The number of eggs emitted by a single fluke may be safely estimated at several hundred thousands. Segmentation of the ovum occurs in the body of the host; but the further development being dependent on a lower temperature than that of the inammalian body, and on moisture, can proceed only after the eggs are discharged. $23^{\circ}$ $26^{\circ} \mathrm{C}$. is most favorable, the embryo being formed in about three weeks. At a lower temperature, the development is prolonged; but, under the same conditions, the individual eggs vary enormously as to described, and call for further study. The embryo is exceedingly active, swimming about like an infusorian, though more rapidly. When it meets a Lymnaeus trunculatus (a common snail), its first host, it presses the head-papilla against the surface of the snail, and begins spinning around its axis, and working its body, until the tissues of the snail are forced apart, leaving a gap through which the embryo squeezes its way into its host. The embryo appears to have some means of instinctively recognizing the trunculatus, for it does not attack other species. It cannot live much more than about twelve hours in water, and it usually gets into a snail within eight hours.

In the snail it changes into a sporocyst, which, during warm summer weather, may leach its full size within a fortnight; but in autumn twice that time 
may be necessary. The outer ciliated cells swell up, and are finally cast off. The embryo then becomes an elliptical cyst, the pigmented eye-spots being still preserved, fig. E. The cyst grows and elongates. The body is then covered by an external cuticle, under which is a sparse musculature, followed by an epithelium, which lines the cavity, and forms the greater part of the thickness of the body-walls. The author gives some further structural details. Sometimes, but less frequently than in other species, these sporocysts multiply by transverse division, effected by a gradually deepening constriction about the middle of the body.

The next larval forms, the rediae, are developed within the sporocyst. The cells, which each give rise to a redia, are in part soon present in the embryo; but they increase later by proliferation of the cells lining the cavity of the sporocyst. The first clearly recognized appearance of the rediae is as a morula-like cluster of cells, which soon assumes the gastrula form. An external membrane appears, and, later, a pharynx. There are several germs in each cyst, usually one redia (less frequently two) nearly ready to leave the sporocyst, with two or three germs of medium size, and several small ones, fig. $B$. When ready to leave the cyst, the redia, by its own motions, makes a forcible exit by rupturing the walls of the sporocyst. The free rediae force their way through the tissues of the host, and are found especially in the liver. They increase in length to $1.3 \mathrm{~mm}$. or 1.6 mm., fig. $\mathbf{C}$; a collar, $q$, being formed, meanwhile, a little behind the pharynx. In other respects, except the possession of a digestive tract, the rediae resemble the sporocysts in structure. They are, however, more muscular, and present other differences, which the author describes. There is present a distinct birth-opening at the side of the body, a little behind the collar, which permits the exit of the brood from within the redia. The germs, $s p$, develop similarly to those of the sporocysts, but are more numerous. Sometimes they form rediae, and sometimes cercariae; yet the early stages of the spores are the same in either case. A germinal cell, forming part of the internal lining of the posterior end of the bodysegments, forms a morula. A gastrula enlarges, and gradually assumes a shape that reveals whether it shall become another redia, or a cercaria. There may be as many as twenty-three spores in various stages of development in one redia. It is probably the temperature which determines whether rediae or cercariae are produced; since the former are produced during the warm, the latter during the cold months.

The development of the cercariae, the next form in the series, takes place, as we have seen, in the redia. As the oval enterate spore increases in size, it assumes a more elongated shape; whilst one end becomes more attenuated than the other, and finally is constricted off to form the tail. The thicker portion becomes the body proper, and in it are developed the bifurcate intestine and other organs. Certain cells, F, later develop into the organs for secreting the cyst; and many of the cells in the body of the cercaria are crowded with most remarkable rod-shaped bodies, G, closely resembling bacteria in size-and shape, reaching a length of $0.006 \mathrm{~mm}$. In an adult redia, with a brood of twenty or so, there will be one, two, or three cercariae approaching complete development.

As soon as the cercaria has reached the limit of development within the redia, it escapes from the parent by the birth-opening. When free, $\mathrm{D}$, the cercaria is very active, and constantly changes its form. Its most striking characteristic is the presence of the cystogenous cells, $\mathrm{D}, c$, before mentioned. These are large, and so crowded with coarse, highly refractile granules as to be rendered quite opaque, F. They are arranged in two-lobed masses, extending along each side of the body, and connected together just in front of the ventral sucker.

By the aid of its suckers, $o$ and $s$, and tail, the tadpole-shaped cercaria crawls or wriggles its way out of its host. When the infested snails are kept, in an aquarium, the cercariae may occasionally be found swimming about in the water, but not long; for, on coming in contact with the side of the aquarium or the water-plants, it proceeds to encyst itself. The process can be readily observed under the microscope for, on a glass slide, the cercaria soon comes to rest. It assumes a rounded form; whilst a mucous substance is poured forth all over the body, together with the granules of the cystogenous cells. The tail is shaken off either before or during encystation, which is completed in a few minutes. These cysts are the means of infecting the final vertebrate host of the parasites; the infection being rendered possible by the habits of the intermediate host, Limnaeus truncatulus, which might well be termed amphibious, so strongly is its habit of wandering on land developed. Indeed, they can remain on land for long periods, and resist even prolonged droughts: hence, when in the water, the snails become infested, and, when on land, leave the cercariae that crawl out of their first host scattered over the fields, where they encyst on the grass, and are eaten by the sheep and other animals.

In the stomach the cyst is dissolved, leaving the worm free. The worm then makes its way into the liver, and probably in about six weeks begins to produce eggs, growing meanwhile. During its growth its external form changes, the simple forked intestine develops many coeca, the posterior sucker is greatly enlarged, and the sexual organs are matured. Thereafter, the wondrous cycle of metamorphoses and emigration recommences with the new eggs. There are, perbaps, no other instances more striking, of the adaptation of animal species to particular conditions of existence, than we find in histories of such parasites as the trematode worms, of which we have narrated one life-history. Charles S. Minot.

\section{FLUORINE MINERALS.}

P. GROTH has carefully reviewed (Zeitschr. kryst., vii. 457 ) the following minerals, mostly from Greenland:-

Pachnolite. - This is shown to be entirely distinct from thomsenolite. The pure crystals were submitted to J. Brandl for analysis, who found that they corresponded closely to the formula $\mathrm{Na} \mathrm{F} . \mathrm{Ca} \mathrm{F}_{2}$. Al $\mathrm{F}_{3}$. It is distinguished from thomsenolite by its absence of water, and has arisen from the analogous mineral cryolite by the substitution of a calcium atom for two atoms of sodium. Heated in the closed tube, the mineral decrepitates violently, covering the sides of the tube with a white powder. The crystals are monoclinic. Almost all show the form of slender prisms, the largest from 2 to $3 \mathrm{~mm}$. long, and 0.5 $\mathrm{mm}$. thick, terminated at one end by an apparently rhombic pyramid, and at the other by two basa planes making a very obtuse angle with one another, showing the twin nature of the crystals. The twinning plane is parallel to the ortho-pinacoid; and the two halves are so equally developed that the two hemipyramids appear above like a very perfect rhombic pyramid. The prismatic faces are finely striated in 